\title{
Plant voltage-dependent anion channels are involved in host defense against Pseudomonas cichorii and in Bax-induced cell death
}

\author{
Chika Tateda $\cdot$ Koji Yamashita $\cdot$ Fumio Takahashi •
}

Tomonobu Kusano · Yoshihiro Takahashi

Published online: 13 June 2009

(c) Springer-Verlag 2009

\section{Erratum to: Plant Cell Rep (2009) 28:41-51}

DOI 10.1007/s00299-008-0630-x

In the above mentioned paper we describe that we used a mouse Bax gene (pro-apoptotic gene) for the analysis of plant programmed cell death. The gene source is incorrect. It is a human Bax cDNA. As both genes are orthologous and a common mammalian pro-apoptotic factor, the conclusion in the paper should not be affected by the error. The authors apologize for the mistake.

The online version of the original article can be found under doi: 10.1007/s00299-008-0630-x.

C. Tateda $\cdot$ K. Yamashita $\cdot$ F. Takahashi $\cdot$ T. Kusano $(\bowtie)$.

Y. Takahashi

Graduate School of Life Sciences, Tohoku University,

2-1-1 Katahira, Aoba, Sendai, Miyagi 980-8577, Japan

e-mail: kusano@ige.tohoku.ac.jp 